\title{
Design rainfalls in a climate changing world
}

\author{
G. Becciu ${ }^{1}$, C. Lewis ${ }^{2}$, S. Mambretti ${ }^{1} \&$ U. Sanfilippo ${ }^{1}$ \\ ${ }^{I}$ DICA, Politecnico di Milano, Italy \\ ${ }^{2}$ Aqua-Assets, LLC, USA
}

\begin{abstract}
Climate changes appear to be altering rainfall patterns. Rainfall intensities which were once accepted for the design of hydraulic structures may no longer be appropriate. With our knowledge about climate change we can no longer use rainfall records as a simple statistical data base. Data trends should be considered. In some areas rainfall depths may be decreasing while in other areas they may be increasing.

In this paper, changes in rainfall depth and duration, which may be due to climate change, have been analysed. This paper focuses on rainfall from Milano, Italy. Some stations in the USA were also analysed to bring a global perspective on changes in rainfall.

For each storm duration, simple linear trend lines were drawn through maximum intensities, producing IDF curves. Trendlines were drawn for the entire years of data and for datasets divided into decades. Kendall Tau tests were used to identify trends. The Pearson test was used to verify the applicability of the Gumbel distribution.

As other authors showed, no trends can be claimed and, therefore, it is still possible to use the commonly adopted methods to estimate the design rainfalls. Keywords: design rainfalls, climate change, rainfall intensity duration frequency.
\end{abstract}

\section{Introduction}

Estimation of extreme rainfall depths and intensities is a central task in water resources engineering. This estimation is usually based on intensity-durationfrequency relationships (IDF) that may be expressed in a parametric form or derived from stochastic modelling. 
Although these relationships are usually simple and the estimation methods are commonly well assessed, some concern is recently arisen about the effects of the possible climate change on the probabilistic reliability of extreme rainfall estimations. Numerous studies in literature highlight effects of climate change scenarios on the rainfall regimes (see e.g. [1, 2]), suggesting that rainfall estimation by traditional approaches, based on the assumption of stationarity and ergodicity of the rainfall record series, could be significantly affected by systematic errors.

It has to be highlighted, however, that climate change affects rainfall not only in terms of annual depths, but also in seasonal distribution, number of rainy days and storm patterns. This means that trends that are significant on some rainfall measure, may be not so for others [3].

Scope of this study is to analyse climate change effects on design rainfalls, that is on extreme rainfall intensities of assigned duration and frequency.

\section{Rainfall databases}

Milano Municipality raingauge network consists in 25 devices placed in 16 stations over the city area and in two towns in the surroundings, plus one installed at the Astronomical Observatory of Brera (still in Milano).

The first of those devices was installed in 1895 on the City Hall; then the large part of the network was implemented in the early twentieth century.

During the seventies, the original Richard tipping bucket raingauges were replaced by SIAP. Finally, since 1999, SIAP digital recording raingauges (with real time data transmission to their control center) are progressively replacing or backing up the previous mechanical devices.

The Milano raingauge network features are definitively quite remarkable, in terms of spatial and temporal extension, devices reliability, data set and resolution. In particular there is a general consensus $[4,5]$ over the significance of Via Monviso raingauge station as the most interesting and significant in Milano, because of its central position in the network and because in 1970 it was one of the first equipped with a SIAP tipping bucket device with mechanical recording and, later, in 2001 it was one of the first equipped with a SIAP tipping bucket device with digital recording. The data base of the rainfall recordings in the years 1971-2012 is used in this paper for analysis. Although earlier data are available, as the two instruments have not been working together, their coherency was not checked and proved, and the two recorded series may be inconsistent.

Moreover, for comparison four locations in Maryland, United States of America (USA), were included. Although there is extensive rainfall data which covers the USA, the focus of this study is the Italian rainfall and the USA data was included for comparison and to demonstrate global implications.

The National Climatic Data Centre (NCDC) complies and publishes on the World Wide Web, rainfall records for a network of over 3600 reporting station located primarily in the United States. Data is collected from a variety of sources including National Weather Service reporting stations, volunteer cooperative 
observers, Federal Aviation Administration (FAA), utility companies, etc. This paper uses the NCDC 15 Minute Precipitation Data; time-sequenced quarterhour precipitation amounts.

The Maryland rainfall database uses data from Fischer-Porter gages between May 1971 and December 1983. The NCDC checked and edited as necessary precipitation values by both automated and manual methods. NCDC data processing procedures were updated in January 1984 to produce the element structured data base files and further enhanced beginning with the January 1996 data month. Currently, interactive quality control procedures are in place that has added many checks and features and data are subjected to automated editing procedures that reduce the manual handling of the data.

\section{Trend of the intensities}

Influence of climate change on rainfall has been analysed in numerous studies reported in literature (see e.g. [1, 6-8]). Although in many of cases significant trends in some characteristics of the rainfall stochastic process have been highlighted, there is not yet a common agreement on the real nature of these trends. The main concern is the relative short length of series of rainfall records, especially when durations longer than one day are considered.

Moreover, in the temperate areas the changes usually observed are in the number of rainy days and on the mean daily rainfall depth, while results on the analysis of rainfall intensities are less clear, generally showing a strong dependence on duration (see e.g. [2, 3]). Other authors [9] clearly state in the series they analyzed no trends can be observed.

Therefore, in this study the concern was to analyse the records of rainfall intensities on a wide range of durations in order, first, to test them for statistically significant trends and, second, to quantify the effects on design rainfalls, that is on IDF curves.

From five series of records the annual maxima of rainfall depths have been extracted for 20 durations, ranging from 5 to 1440 minutes ( 24 hours). For all durations a least square linear function of the rainfall depths $V s$ time was fitted, with the results shown in table 1 . In figure 1 data for 20 and 1440 minutes are also shown.

As can be seen from table 1, in some cases the observed trends are positive, in others negative. In all cases, trends of the annual maxima seem evident, although data are very scattered. However, the sign of these trends are not the same for all the stations and all the durations. For Millers4 station a positive trend is observed, with increasing gradient, while for Aberdeen and Beltsville the trend is negative for durations until 720 minutes (12 hours) and positive for the longer durations. The opposite happens for Milano station, with positive gradients for durations up to 720 minutes and negative for longer ones. An analogous behaviour is observed for Unionville, with breakpoint at 90 minutes.

In the case of Milano and, partially, of Unionville, the positive trend for shorter duration and the practical invariance for larger durations seems in agreement with the common idea that climate change increases the frequency of 
extreme events, of shorter duration and higher mean rainfall intensities, while the average values remain constant. However, results are not homogeneous and a clear statement cannot be made.

Data recorded in the USA (and their interpretation) are more complicated because of the presence of the seasonal El Niño and La Niña. These phenomena are usually considered climatic anomalies, not climate changes. So they can interfere with any estimation of the rainfall regime evolution related to climate changes properly said for large part of the world including North America coastal areas [10-13]. Nonetheless, there are other extended regions in the world, including Europe, Mediterranean Sea and central part of Asia, where El Niño and La Niña effects are negligible, and therefore the analysis of climate changes in those regions in not supposed to need to keep them into account.

The years when El Niño and La Niña were stronger are reported in table 2, while in table 3 the gradient of the trend lines for the USA stations not accounting the years of the seasonal instabilities are shown. As can be seen, the removal of these data does not clarify the trends, which values change but without giving a definite answer.

As mentioned, Italian data, and in particular the Milano rainfall regime, are not affected by El Niño and La Niña, and therefore the performed analysis does not need to be corrected.

Table 1: Gradient of the trend line for one Italian station and four USA stations.

\begin{tabular}{|c|ccccc||}
\hline \hline $\begin{array}{c}\text { Duration } \\
{[\mathrm{mm}]}\end{array}$ & Milano & \multicolumn{4}{c|}{$\begin{array}{c}\text { Unionville } \\
\text { Gradient of the trend line }\end{array}$} \\
\hline 5 & 0.0221 & 0.0228 & 0.0155 & -0.0176 & -0.0286 \\
10 & 0.0719 & 0.0228 & 0.0155 & -0.0176 & -0.0286 \\
15 & 0.0839 & 0.0205 & 0.0161 & -0.0114 & -0.0206 \\
20 & 0.0907 & 0.0205 & 0.0161 & -0.0114 & -0.0206 \\
30 & 0.1184 & 0.0198 & 0.0186 & -0.0100 & -0.0180 \\
45 & 0.1677 & 0.0162 & 0.0200 & -0.0085 & -0.0172 \\
60 & 0.1857 & 0.0117 & 0.0213 & -0.0114 & -0.0158 \\
90 & 0.1685 & 0.0015 & 0.0261 & -0.0070 & -0.0148 \\
120 & 0.2076 & -0.0030 & 0.0312 & -0.0053 & -0.0141 \\
180 & 0.1599 & -0.0034 & 0.0342 & -0.0040 & -0.0131 \\
240 & 0.1630 & -0.0080 & 0.0359 & -0.0034 & -0.0124 \\
300 & 0.1759 & -0.0190 & 0.0378 & 0.0012 & -0.0127 \\
360 & 0.2298 & -0.0289 & 0.0382 & 0.0012 & -0.0116 \\
420 & 0.2343 & -0.0321 & 0.0423 & 0.0017 & -0.0073 \\
480 & 0.2160 & -0.0356 & 0.0511 & -0.0006 & -0.0055 \\
540 & 0.1726 & -0.0413 & 0.0544 & -0.0058 & -0.0046 \\
600 & 0.1449 & -0.0462 & 0.0553 & -0.0076 & -0.0053 \\
720 & 0.0996 & -0.0483 & 0.0571 & -0.0060 & -0.0029 \\
1080 & -0.0336 & -0.0595 & 0.0840 & 0.0021 & 0.0063 \\
1440 & -0.0458 & -0.0558 & 0.0998 & 0.0054 & 0.0070 \\
\hline \hline
\end{tabular}




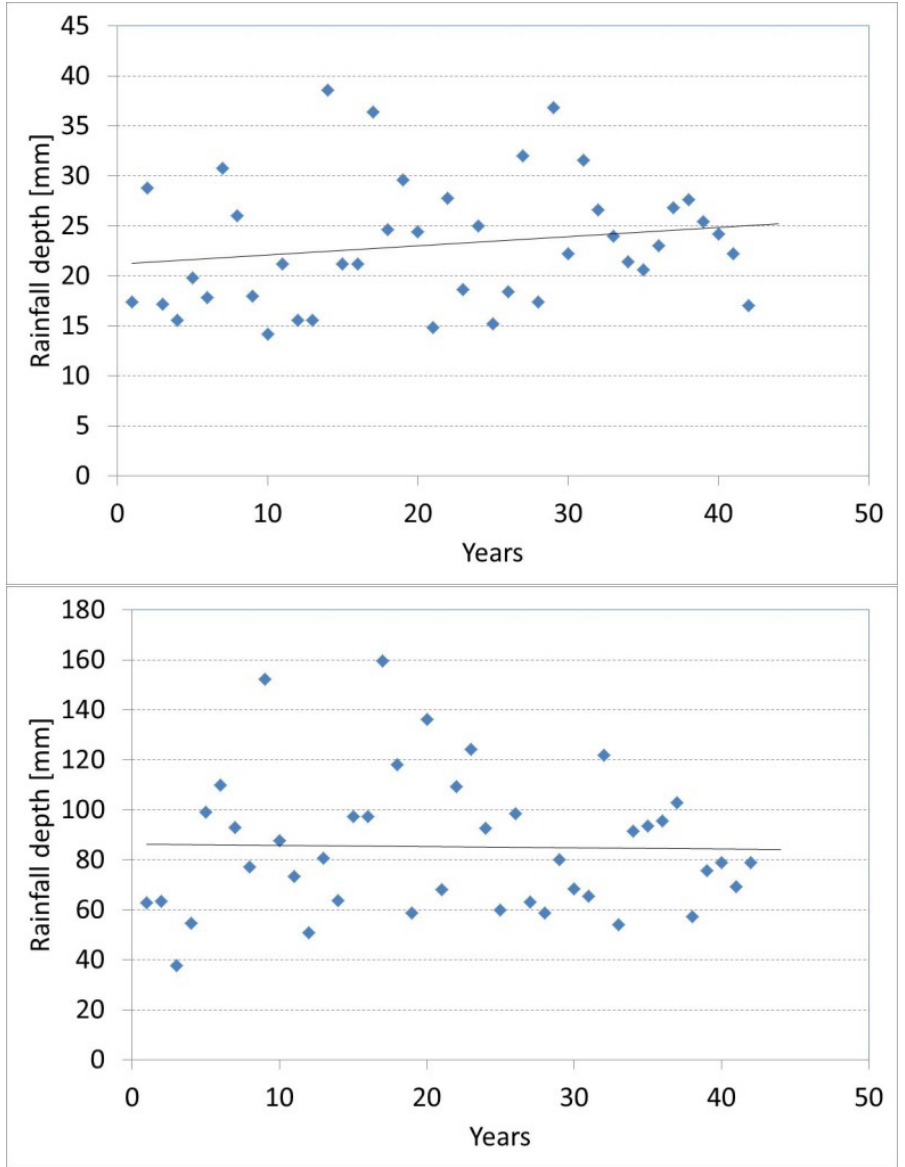

Figure 1: Rainfall depths for 41 years historical series at Milano's raingauge: 20 minutes (above) and 1440 minutes (below) durations.

Table 2: Years when the seasonal instabilities were stronger in the USA.

\begin{tabular}{||c|c|}
\hline \hline El Niño & La Niña \\
\hline 1957 & 1973 \\
1965 & 1975 \\
1972 & 1988 \\
1982 & 1999 \\
1997 & 2010 \\
\hline
\end{tabular}

In any case, it can be observed that trend gradients are not so high, except for Milano, especially if compared to averages of rainfall depth maxima. In figure 2 the ratio of gradient of linear regression line and average (maxima rainfall depths for Milano station is shown for the different durations. 
Table 3: Gradient of the trend line the USA stations having removed the years when El Niño and La Niña were influential.

\begin{tabular}{||cccc||}
\hline $\begin{array}{c}\text { Unionville } \\
\text { reduced }\end{array}$ & $\begin{array}{c}\text { Millers4 } \\
\text { reduced }\end{array}$ & $\begin{array}{c}\text { Aberdeen } \\
\text { reduced }\end{array}$ & $\begin{array}{c}\text { Beltsville } \\
\text { reduced }\end{array}$ \\
\hline 0.0200 & 0.0141 & -0.0112 & -0.0090 \\
0.0200 & 0.0141 & -0.0112 & -0.0090 \\
0.0132 & 0.0155 & -0.0050 & -0.0034 \\
0.0132 & 0.0155 & -0.0050 & -0.0034 \\
0.0139 & 0.0188 & -0.0040 & -0.0012 \\
0.0113 & 0.0211 & -0.0014 & -0.0022 \\
0.0104 & 0.0227 & -0.0039 & -0.0008 \\
0.0019 & 0.0287 & 0.0020 & 0.0002 \\
-0.0008 & 0.0348 & 0.0040 & 0.0008 \\
0.0020 & 0.0394 & 0.0055 & 0.0016 \\
-0.0012 & 0.0401 & 0.0053 & 0.0008 \\
-0.0081 & 0.0419 & 0.0101 & -0.0023 \\
-0.0081 & 0.0410 & 0.0104 & -0.0008 \\
-0.0037 & 0.0447 & 0.0106 & 0.0003 \\
-0.0022 & 0.0526 & 0.0078 & 0.0015 \\
0.0020 & 0.0558 & 0.0061 & 0.0018 \\
-0.0011 & 0.0573 & 0.0045 & 0.0007 \\
0.0009 & 0.0584 & 0.0069 & 0.0040 \\
0.0019 & 0.0906 & 0.0158 & 0.0189 \\
0.0121 & 0.1039 & 0.0162 & 0.0189 \\
\hline
\end{tabular}

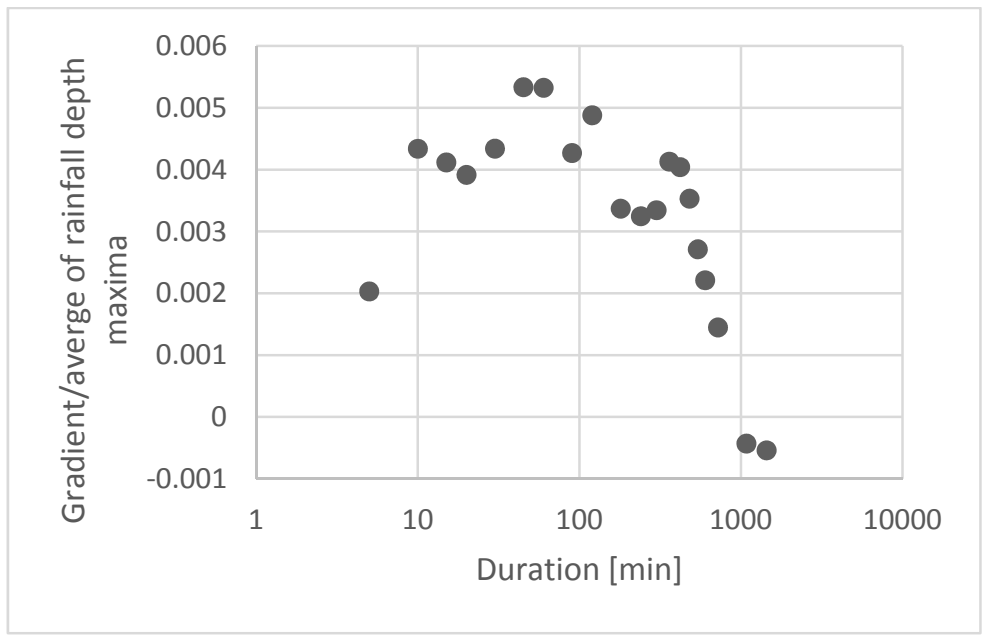

Figure 2: $\quad$ Ratio of gradient of linear regression line and average maxima rainfall depths for Milano station for the different durations. 
Table 4: Result of Kendall Tau trend test for annual maxima series of rainfall depths recorded in Milano station.

\begin{tabular}{||c|c||}
\hline $\begin{array}{c}\text { Duration } \\
{[\mathrm{min}]}\end{array}$ & $R_{\tau}$ \\
\hline 5 & 0.36 \\
10 & 1.31 \\
15 & 1.33 \\
20 & 1.27 \\
30 & 1.25 \\
45 & 1.29 \\
60 & 1.48 \\
90 & 1.16 \\
120 & 1.20 \\
180 & 0.92 \\
240 & 0.94 \\
300 & 1.31 \\
360 & 1.42 \\
420 & 1.53 \\
480 & 0.99 \\
540 & 0.79 \\
600 & 0.73 \\
720 & 0.38 \\
1080 & 0.12 \\
1440 & 0.05 \\
\hline
\end{tabular}

To better investigate the nature of the observed trends for the station of Milano, some statistical tests were performed to verify their significance. To verify the existence of a monotonic trend in the series of annual maxima of rainfall depths the Kendall Tau test was performed for all the 20 durations. This non-parametric test is based on the statistic:

$$
\tau=\frac{4 \cdot p}{N \cdot(N-1)}
$$

where $p$ is the number of times in a series of $N$ records $x_{i}$ in which results $\left(x_{i}<x_{j}\right.$; $i=1,2, \ldots N ; j=i+1, i+2, \ldots, N)$. For a random sequence it can be shown that [14]:

$$
\begin{aligned}
& E[\tau]=0 \\
& V A R[\tau]=\frac{2 \cdot(2 \cdot N+5)}{9 \cdot N \cdot(N-1)} \\
& \lim _{N \rightarrow \infty} \frac{\tau}{\sqrt{\operatorname{VAR}[\tau]}}=\lim _{N \rightarrow \infty} R_{\tau}=\mathcal{N}(0,1)
\end{aligned}
$$

Therefore, if $R_{\tau}$ is within the limits \pm 1.96 , the null hypothesis of no trend in the series cannot be rejected at the 5\% level of significance. As can be seen in table 4, where results of the test are reported, the observed trends are not statistically significant for all 20 durations. 
Although for limited recordings, the Maryland station of Unionville (years 1971-1995 included) and Millers 4 (years 1988-2011 included) show the same trend. However, the same trend is not confirmed for all the stations available at the date the paper was written: for instance the stations of Aberdeen (years 1979-2011) and Beltsville (years 1971-2011) show a very different trend.

\section{Intensity-duration curves}

However, trends have to be investigated also in making design curves, as it is clear that if the rainfalls change during the years, and therefore the recorded intensities, the series cannot form a single data base to be used to compute the intensity-duration curves, but the trends should be considered and included in the evaluations of the design curves.

A possible approach to this problem is to limit the IDF calibration to recent records only, in order to give more "weight" to possible on-going climate trends. Anyway, it is clear that the shorter length of the record series considered in the calibration significantly reduces the reliability of estimates.

An alternative is to de-trend the record series for IDF calibration and then to consider a time-varying function for the rainfall intensity mean values. This can be done if the trend is statistically significant and not due to small scale periodic fluctuation around the mean.

First evaluations were performed on the Italian data base and the curves were in the form:

$$
i[m m / h]=\frac{A(T)}{(B(T)+\vartheta[h])^{C(T)}}
$$

where $i$ is the expected intensity for the duration $\vartheta$, while $A, B$ and $C$ are the computed parameters for the intensity-duration curve, function of the return period $T$.

These first evaluations consisted in computing the mentioned curves dividing the entire data base in decades: therefore using the available data for the first ten years (1971-1980) to carry out a curve, then the second ten years (1981-1990), and the third (1991-2000) and fourth (2001-1010) ten year series.

Quite unexpectedly, at least for the authors, the trend which has been clearly identified and reported above, is not echoed in the curves. In fact, for instance, the curves carried out using the first ten years (1971-1980) are below those carried out using the last ten years (2001-2010) series.

This result is to be ascribed to the effects of the intensities for longer durations and, therefore, in the paper we decided to use of the "old" binomal curves, in the form:

$$
i=a(T) \cdot \vartheta^{n(T)-1}
$$

where again $i[\mathrm{~mm} / \mathrm{h}]$ is the expected intensity for the duration $\vartheta[h]$, while $a$ and $n$ are the computed parameters for the intensity-duration curve, function of 
the return period $T$. This two-parameter curve cannot be used for the whole range of durations, from small to large, and normally two couples of parameter were used: the former for smaller durations (up to one hour or less) and the latter for larger durations.

The values of the parameter $a$ of the equation (6) has been estimated using a "mobile" data base of ten years, starting from the period (1971-1980) and going on with (1972-1981) and continuing until (2003-2012). The carried out values are plotted in figure 3.

It is interesting that the two data sets converge after an hour, that explaining the contradictory results that have been carried out using the three-parameters curve.

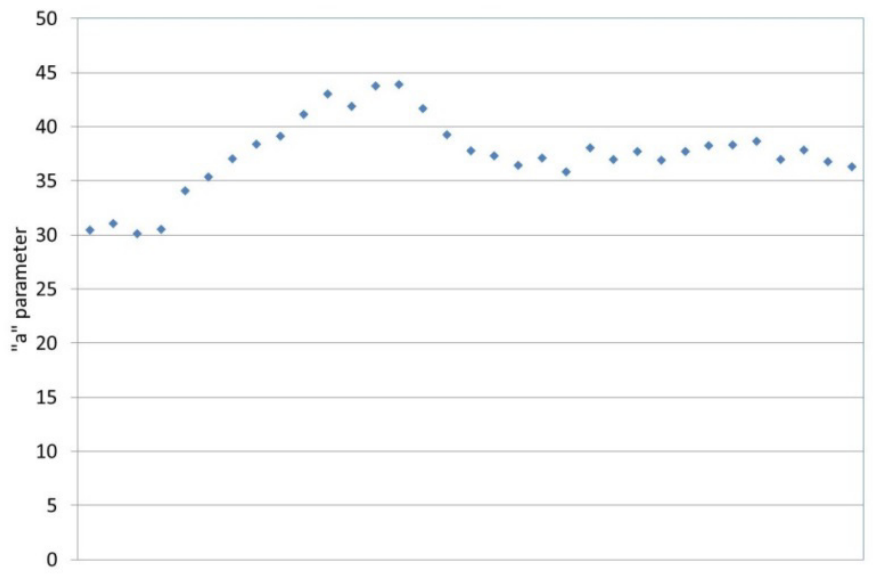

Figure 3: $\quad$ Parameters $a$ for the IDF curves computed for short durations, with mobile average upon 10 years $(\mathrm{T}=2$ yrs, $n=0.491)$.

There appears to be more variation between the data sets between the shorter duration storms than the longer duration storms. This might suppress any normally apparent patterns or trends. However it would still appear that there might be trend for more high intensity thunder storms, which may be associated with longer term climatic changes in the global temperature.

Finally, analysis using the Gumbel probabilistic chart have been performed: on the entire set of data (figure 4), on the last 25 years (i.e. in the period 19882012) and on the entire set of data except the year 1987, when a very intense event occurred (the latter two charts are not reported because of the limited space). The event in 1987 is still unsurpassed in intensity, and was much higher than the second highest recorded event. As can be seen in the mentioned figure (other charts are very similar) only the highest values do not fit the probabilistic law; in this case, the Pearson test has not passed, but for a small amount (the computed value is equal to $\chi^{2}=39.00>\chi_{\max }^{2}=37.65$ using 28 classes $)$. 

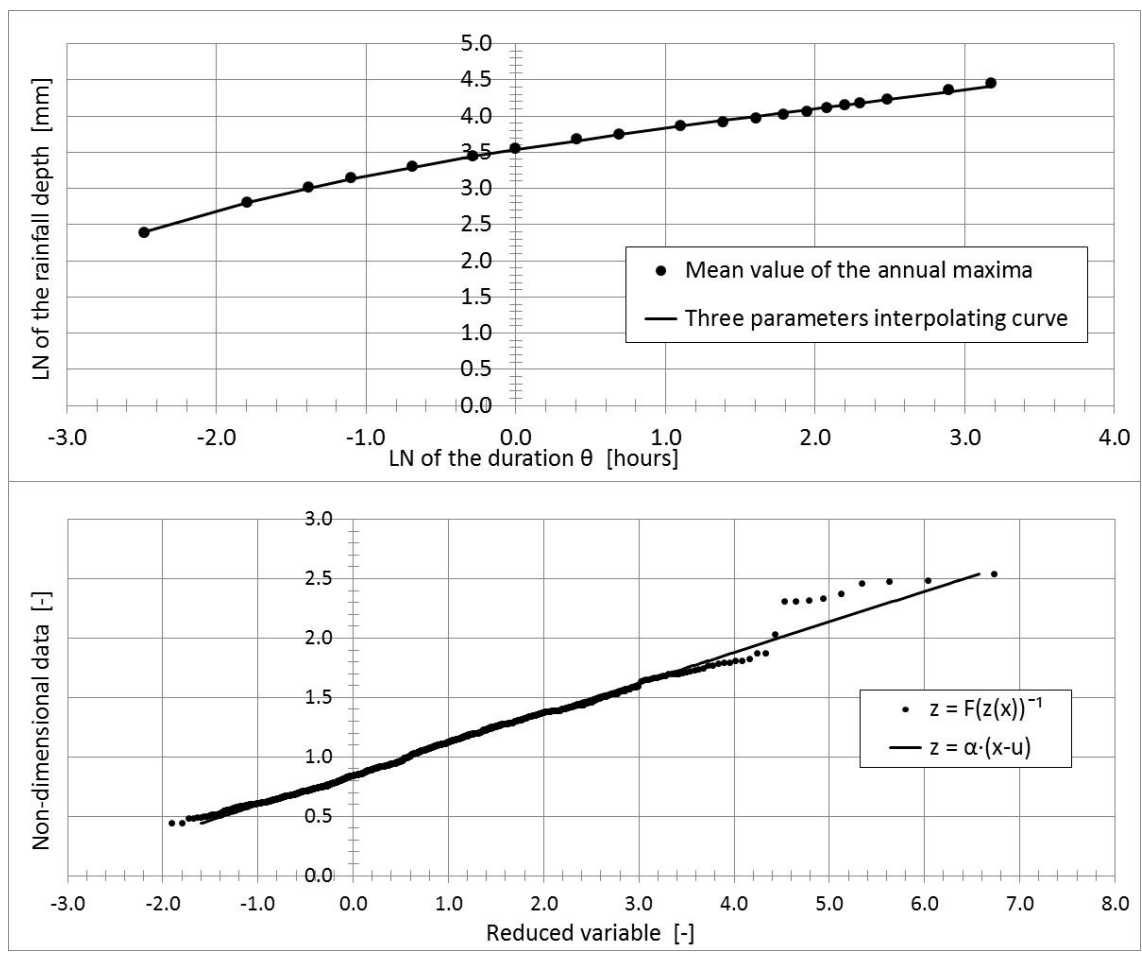

Figure 4: $\quad$ Milano (1971-2012): mean value of the annual maxima. (Above): three parameters interpolating curve. (Below): Gumbel plotting position chart for the non-dimensional data.

\section{Conclusions}

A proper estimation of extreme rainfall depths and intensities is a central task in water resources engineering and used for designing hydraulic structures.

Although the usual relationships are quite simple and the estimation methods are well assessed, some concern is recently arisen about the effects of the possible climate change on the probabilistic reliability of extreme rainfall estimations. In fact, if the rainfalls change during the years, and therefore the recorded intensities, the series cannot form a single data base to be used to compute the intensity-duration curves, but the trends should be considered and included in the evaluations of the design curves.

In the present paper, the climate change effects on design rainfalls have been analysed, using historical rainfall data series recorded in Italy and in the USA.

Analysis has been carried out using simple trend lines over the maxima intensities, producing IDF curves (also using sub sets and dividing the series in decades) and applying Kendall Tau tests for trend and verifying the adoptability of the Gumbel distribution with the Pearson test. 
As other authors showed (e.g. [9]), no trends can be claimed. Obviously, this does not imply the effects of the climate change does not exist, as they can be observed in the temperature changes and in other well-known phenomena associated with it. That simply means that, at the moment, the recorded rainfalls changes cannot be quantified. As the rainfall changes are not quantified, it is still acceptable to use the commonly adopted methods to estimate the design rainfalls.

Further research is needed to assess the trends in other regions and as time progresses. As more data becomes available changes due to the climate variations should be evaluated further.

\section{References}

[1] Karl TR, Knight RW, Plummer N. 1995. Trends in high-frequency climate variability in the twentieth century. Nature 377: 217-220.

[2] Brunetti M., Buffoni L., Maugeri M., Nanni T. 2000. Precipitation trends in northern Italy, Int. J. Climatol. 20: 1017-1031.

[3] Yu B, Neil DT. 1991. Global warming and regional rainfall: the difference between average and high intensity rainfalls. International Journal of Climatology 11: 653-661.

[4] Brown M., Cao C., Gentile A., Maione U., Mignosa P., Paoletti A., Passoni G., Piga E. 1990. Le serie pluviografiche complete della città di Milano. Primo rapporto: le stazioni di via Monviso (1971-1987) e di Monluè (1977-1987). Città Studi, Milano (in Italian).

[5] Piga E., Salis M., Passoni G. 1990. Analisi statistica delle piogge intense di breve e brevissima durata nell'area metropolitana di Milano. Città Studi, Milano (in Italian).

[6] Schönwiese CD, Rapp J. 1997. Climate Trend Atlas of Europe Based on Observations 1891 - 1990. Kluwer Academic Publishers: Dordrecht.

[7] Sneyers R., Palmieri S., Siani A.M., 1993. Characterizing trends in climatological time series. An application to Brera observatory (Milan) rainfall series. Proceedings of international conference on applications of time series analysis to astronomy and meteorology, Università di Padova, 6-10 Sept. 1993, pp. 321-328.

[8] Piervitali E, Colacino M, Conte M. 1997. Signals of climatic change in the central-western Mediterranean Basin. Theoretical and Applied Climatology 58: 211-219.

[9] Portela M.M., Santos J. F., Quintela A. C., Vaz C. 2009 Trends in hydrologic time series River Basin Management $V$ C.A. Brebbia (Ed.), WIT Press, Southampton, 185-195.

[10] Lee S.K., Chunzai W., Enfield D.B. 2008. Why do some El Niños have no impact on tropical North Atlantic SST? Geophysical Research Letters 35 (L16705).

[11] Solomon S., Qin D., Manning M., Chen Z., Marquis M., Averyt, K.B. Tignor M., Miller H.L. Climate Change 2007: The Physical Science Basis. Contribution of Working Group I to the Fourth Assessment Report of the 
Intergovernmental Panel on Climate Change. Cambridge University Press, UK.

[12] Yamasaki K., Gozolchiani A., Havlin S. 2008. Climate networks around the globe are significantly affected by El Nino. Physical Review Letters 100 (3): 228501.

[13] Yeh S.W., Kug J.S., Dewitte B., Kwon M.H., Kirtman B.P., Jin F.F. 2009. El Niño in a changing climate. Nature 461 (7263): 511-4.

[14] Kottegoda N.T. 1980. Water Resources Technology. McMillan, London. 